\title{
Leprosy in Pakistan
}

\author{
RUTH PFAU* \& GHAZALA HAQ $\dagger$ \\ *Marie Adelaide Leprosy Centre, PO Box 8666, Mariam Manzil, \\ Karachi 03; $†$ Pakistan Medical Research Council, Research Centre, \\ Karachi 35, Pakistan
}

Accepted for publication 11 September 1985

\begin{abstract}
Summary Refugee movements, including the variable influx of Afghans and Biharis (the former with a considerable percentage of infectious cases), create logistic and administrative difficulties, calling for new approaches to ensure regularity of attendance, compliance to the ingestion of prescribed medication and the adequate supervision of both staff and patients. However, progress has certainly been made; deformity rates are stabilizing and in at least one part of the country (Azad Kashmir), with a static population and good work performance, incidence rates have dropped. If we can extend and maintain the implementation of multiple drug therapy, there is a realistic hope that over $80 \%$ of our cases can be treated and discharged within the next 8 years.
\end{abstract}

Leprosy work in Pakistan began in August 1955 when the Archbishop of Karachi, the late Monsignor van Mittenberg, asked for help with 124 leprosy patients in the beggar colony. In 1957 UNILEF and the Catholic Relief Association combined to give assistance. In 1960 the number of patients reached 500 and the regular registration of patients began.

In 1979, an issue of the WHO Weekly Epidemiological Record ${ }^{1}$ quoted a 1975 figure of 9,573 cases registered and 20,000 estimated, but in 1983, Kaleta, in his Assignment Report to WHO, ${ }^{2}$ recorded 17,068 cases 'under treatment'. Based on the 1981 census, the population of this country was $84,253,644$ and currently we have about 30,000 cases registered. Control programmes are now established in the whole of Pakistan, including 7 subcentres in Karachi and 40 field clinics in other provinces. Leprosy control units have been established in all provinces of Pakistan, Acad Kashmir and the northern areas with the cooperation of the Federal and Provincial Governments and Voluntary Agencies. To date there are 85 Leprosy Control Units all over the country. Prevalence rates are shown in Figure 1. The areas of highest prevalence are Karachi, Mahal Kohistan in Dadu, 


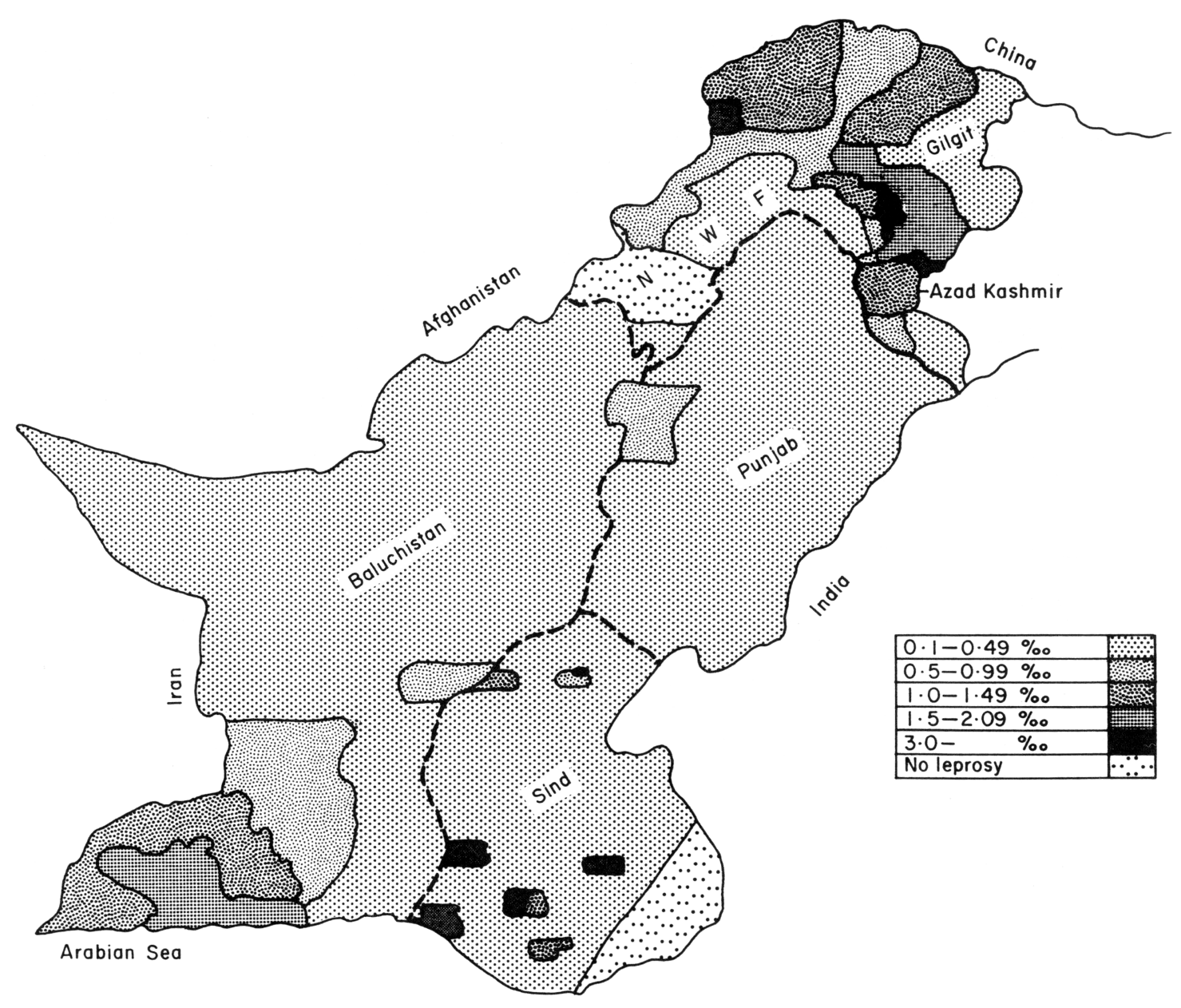

Figure 1. Leprosy prevalence rates in Pakistan. 
Kankot in Jaccoabad, Azad Kashmir, Kohata and Atmogoa Tehsir in Azad Kashmir, Kohistan district and the Wajai tribal agency in NWFP.

\section{Methodology of leprosy control}

Under the Directorate of Health Services and the District Health Officer are (provincial) leprosy field officers and district leprosy controllers, who in turn supervise leprosy technicians. From leprosy clinics and control centres, trained personnel go into the field in search of new cases, and to survey the whole population, especially in the endemic areas. Figure 2 shows the centres that have been established all over Pakistan for leprosy control. Overall there are four provinces in Pakistan in which Sind has 14 centres, Punjab 10, North-West Frontier Province 34 and Balu-chistan 8. Azad Kashmir, though independent of Pakistan, has been included in our study and has 39 provinces. Northern areas have four centres. The majority of registered patients at the present time are to be found residing in Karachi, in which Mangopeer has also been included since 1983. Karachi has $61 \%$ of the patients. Among other provinces, NWFP contributes $18 \%$ while northern areas of Azad Kashmir contribute 15\%. The new admissions in 1983 saw an increase of $18.5 \%$ as compared to 1982 . Sind Province contributed 721 of all the new cases. Baluchistan saw an increase of $1 \%$ as compared to 1982 and in Punjab the new admissions went up by $2 \%$. NWFP is the only province showing a definite decline in the number of new admissions from $16 \%$ in 1982 to $11 \%$ in 1983 .

Deformity rates in Pakistan have remained stable at $21 \%$ in 1982 and $22 \%$ in 1983. Greater Karachi, with a good performance in case finding, has a low deformity rate of only $13 \%$, whilst Mangopeer has the highest deformity rate of $37 \%$ followd by Baluchistan at 33\%. Reduction of deformity rate has been achieved in NA from 53 to $20 \%$ and NWFP from 31 to $28 \%$ while a certain increase has been registered in Sind rural (10\%), Punjab (8\%) and Azad Kashmir $(6 \%)$.

The female rate in Pakistan generally has slightly declined from $38 \%$ in 1982 to $35 \%$ in 1983 but the rate in Greater Karachi is $49 \%$ and in Sind $50 \%$, both much above the national average.

Rates for regularity of attendance have surpassed the $70 \%$ mark in many provincial control programmes, including Greater Karachi, and in several it is above $80 \%$. But in recent years there has been a drop in Sind rural and very low figures have been recorded for Mangopeer. We should emphasize, however, that currently available figures include a considerable number of patients who are totally absent and extremely difficult to trace. 


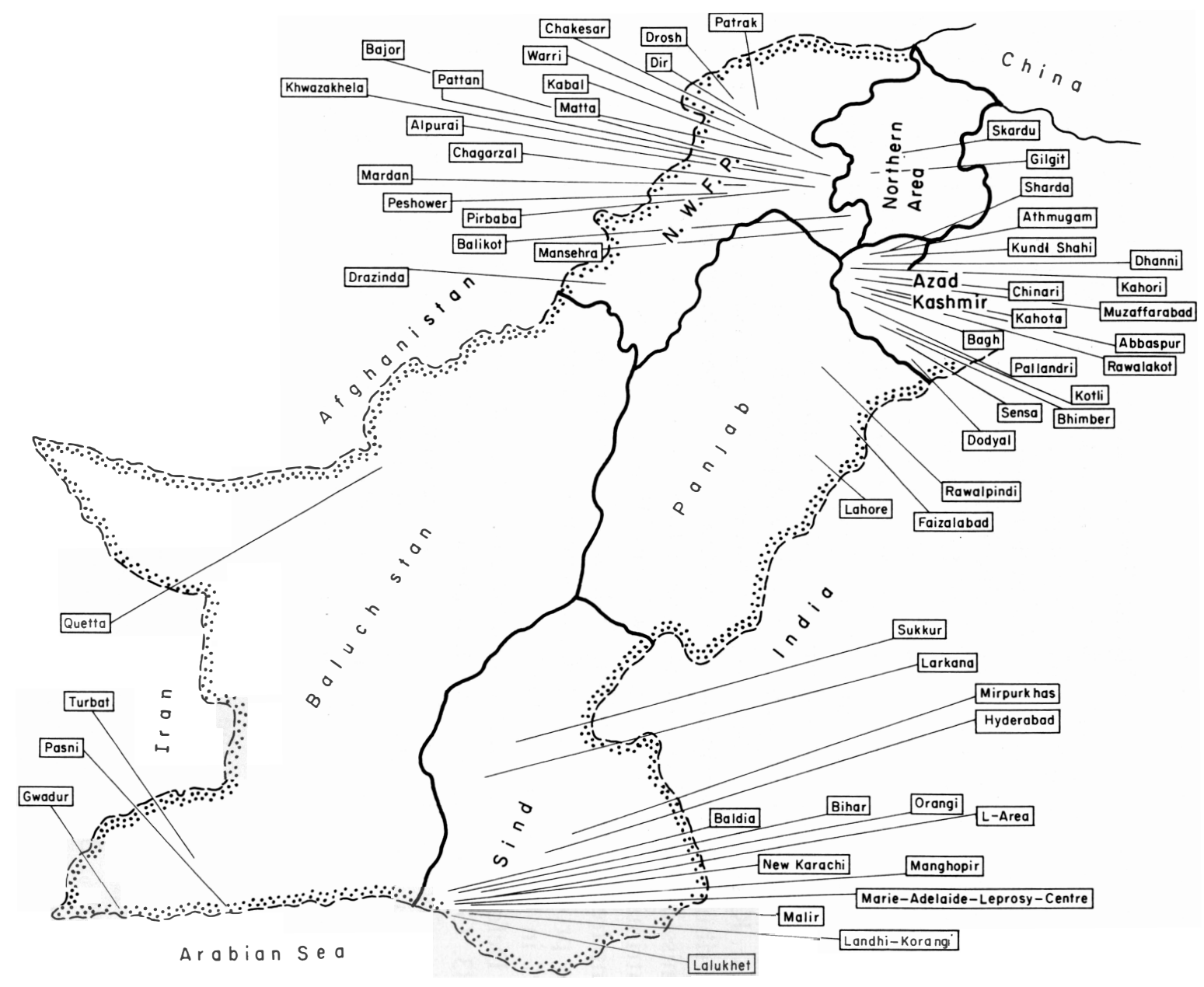

Figure 2. Leprosy control centres in Pakistan, 1 May 1980. 


\section{Chemotherapy}

In the period 1960-68, dapsone monotherapy was used in a dose of $10 \mathrm{mg} / \mathrm{kg} /$ week, started in low dosage, and gradually increased. In the period 1969-74, this was reduced to $7 \mathrm{mg} / \mathrm{kg} /$ week. From 1975 to 84, bacteriologically negative (BI negative) cases were treated with dapsone $7 \mathrm{mg} / \mathrm{kg} /$ week and all positive cases with dapsone $10 \mathrm{mg} / \mathrm{kg} /$ week, plus clofazimine $400 \mathrm{mg} /$ week for 6 months, followed by dapsone $10 \mathrm{mg} / \mathrm{kg} /$ week. In 1984, multiple drug therapy as advised by $\mathrm{WHO}^{3}$ was started in project areas in all provinces of Pakistan, but only polar tuberculoid cases were accepted as 'pauci-bacillary', all others being treated with the triple drug regimen (dapsone, clofazimine and rifampicin) for a minimum of 2 years.

\section{References}

1 WHO. Weekly Epidemiological Record, No. 3, 1979, 17-23

2 WHO. Assignment Report. A visit to Pakistan in relation to leprosy control. 8th May-6th June 1983. Dr J Kalata, WHO Consultant. EM/LEP/34 EM/PAK/BVM/001/RB

3 WHO Study Group. Chemotherapy of leprosy for control programmes. Technical Report Series No. 675. WHO: Geneva, 1982 